DOI 10.37882/2223-2982.2021.08.36

\title{
МУЛЬТИМОДАЛЬНАЯ КРЕАТИВНОСТЬ В КОНТЕКСТЕ АНТРОПОЦЕНТРИЗМА (НА МАТЕРИАЛЕ АНГЛИЙСКИХ И ФРАНЦУЗСКИХ МЕМОВ ЭПОХИ ПАНДЕМИИ)
}

\section{MULTIMODAL CREATIVITY IN THE CONTEXT OF ANTHROPOCENTRISM (ON THE MATERIAL OF ENGLISH AND FRENCH MEMES OF THE PANDEMIC ERA) \\ M. Taymour \\ E. Tulubeeva}

Summary: This article is devoted to the study of the main anthropological characteristics and functions of English-language and French-language Internet memes during the COVID-19 pandemic. The article presents the results of the analysis of the creative potential of multimodal memes expressing the position in relation to the pandemic of the groups of "covid-loyalists" and "covid-alarmists". The processes of functioning of the cognitive mechanisms of information compression and conceptual integration are studied.

Keywords: anthropocentrism, internet meme, pandemic, multimodality, virtual discourse, compression of information, conceptual integration.
Таймур Мария Павловна

К.филол.н., старший преподаватель, Московский государственный лингвистический университет mariataymour@gmail.com

Тулубеева Елена Валерьевна

К.филол.н., доцент, Московский государственный лингвистический университет evtulubeeva@mail.ru

Аннотация: Данная статья посвящена исследованию основных антропологических характеристик и функций англоязычных и франкоязычных интернет-мемов периода пандемии COVID-19. Представлены результаты анализа креативного потенциала мультимодальных мемов, выражающих позицию по отношению к пандемии групп «ковид-лоялистов» и «ковид-паникеров», а также изучаются процессы функционирования когнитивных механизмов компрессии информации и концептуальной интеграции.

Ключевые слова: антропоцентризм, интернет-мем, пандемия, мультимодальность, виртуальный дискурс, компрессия информации, концептуальная интеграция.
$\Pi$ андемия COVID-19, охватившая мир в марте 2020 года, стала катализатором многочисленных исследований новых процессов и явлений. В отечественной и зарубежной лингвистике особое внимание уделяется различным виртуальным дискурсам и концептуальным мирам, моделирующим социальную реальность в Интернете, где формы социокультурного и межличностного взаимодействия во всех сферах жизни человека за данный период достигли качественно и количественно другого уровня. Антропоцентризм остается ведущим направлением исследований, основным объектом которых выступают коммуникативный треугольник «автор - текст - адресат». Научному анализу и переосмыслению подвергается языковая личность, ее саморепрезентативность, способы взаимодействия и средства коммуникации в Интернет-среде, а также феномен креативности человека, усложнения ее форм и видов вследствие создания различных мультимодальных текстов с разными способами передачи контента (вербальные, аудиальные, визуальные и др.). Результаты когнитивных исследований, проведенных за последние десять лет, показывают, что в виртуальной реальности практически наибольшим креативным потенциалом обладают интернет-мемы [Канашина 2016; Марченко 2013; Рябых 2019; Таймур 2020 и др.].
Продолжающаяся пандемия провоцирует перерождение уже существующих и появление новых мемов, спонтанно возникающих и широко тиражируемых на виртуальных платформах, в социальных сетях и сообществах с многотысячной аудиторией. На многих англоязычных и франкоязычных веб-сайтах «ветка» с мемами про пандемию набирает почти столько же подписчиков, сколько «ветка», содержащая официальную информацию про ситуацию с COVID-19. Невозможно не заметить сходство циклов жизни интернетмема и вируса: оба стихийно возникают, стремительно распространяются по всему миру, достигают пика развития и постепенно исчезают, вытесняясь другими видами себе подобных.

В современной науке мем понимается как некий концепт, информация, идея, распространяемая в онлайн-среде. Изучение пандемических мемов на разных европейских языках в контексте антропоцентризма представляется актуальным по следующим причинам:

1. Интернет-мемы интегрированы в глобальные процессы, происходящие в мировом сообществе [Канашина 2016], следовательно, они репрезентируют злободневные концепты, актуальные в когнитивном и эмоциональном плане как для отдель- 
ного индивида, так и для различных социальных групп в целом;

2. Пандемические языковые креативные игры определяются антиномией между основополагающей интенцией европейской культуры на утверждение индивидуальной свободы и стремлением к научно-техническому контролю над миром [Boронов 2021];

3. Мемы становятся одним из ведущих средств интернет-коммуникации в условиях принятых ограничений в силу их семантической емкости и прагматического потенциала, который обладает высокой степенью аффективности и апеллирует к эмоциям адресата;

4. Период пандемии отмечен формированием различных в культурно-информационном отношении групп: ковид-паникёры, ковид-лоялисты, ковид-скептики и ковид-диссиденты [Воронов 2021], которые по-разному оценивают степень опасности вируса, пользу ограничительных мер и т.п., и транслируют свое отношение к вызовам пандемии, выражая различные мнения, оценочные суждения, используя языковые игры в разных дискурсах. Коллективно-творческий, фольклорный характер мемов позволяет идентифицировать конкретные группы, использующие креативный потенциал интернет-мемов для выражения своей позиции;

5. Юмористически-развлекательный характер мемов определяет их регуляторную психическую функцию воздействия на адресата: мемы помогают легче пережить новый экзистенциальный опыт, вызванный пандемией (опыт психологической актуализации близости болезни, смерти или утраты, а также опыт переживания разрыва с близкими и необходимости соблюдения ограничительных мер). Подтверждением актуальности и силы прагматического воздействия мемов может служить выставка "25.000 COVID Jokes (it's not a joke)" итальянской арт-художницы Паолы Пиви в Марселе, на которой представлены интернетмемы и шутки, созданные за 18 месяцев пандемии в 60 странах мира. Их обширная география и внушительное количество свидетельствуют о том, что в период изоляции представители практически всех национальностей находит психологическую компенсацию в генерировании подобных креативных феноменов.

Настоящая работа посвящена анализу креативного потенциала мультимодальных англоязычных и франкоязычных мемов периода пандемии, где мультимодальность понимается как наличие нескольких компонентов, относящиеся к разным семиотическим системам, взаимодействие которых и формирует семантику мема.

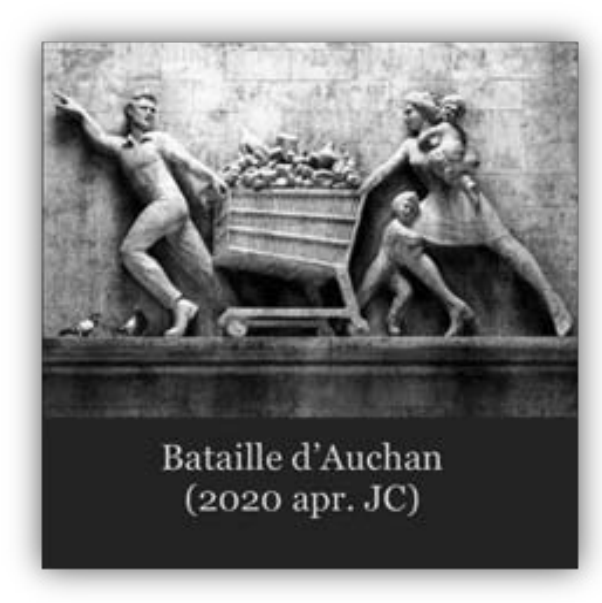

Рис. 1. Битва в Ашане

Эмпирическую базу для нашего исследования составили 200 мемов из ведущих англоязычных и франкоязычных интернет-сайтов и изданий. Для анализа были отобраны статичные мемы, где в качестве визуального компонента используется неподвижное изображение, которые репрезентируют ситуацию «человек в условиях изоляции», где наиболее частотные коммуникативные намерения авторов подборок - позабавить, помочь справиться с депрессией или побороть страх, укрепить социальные связи, разрядить атмосферу в семье, выплеснуть ярость на власть имущих или на нарушителей карантина, вновь почувствовать себя хозяином своей судьбы. Антропоцентром исследуемых мемов является концепт «человек», среди составляющих которого в результате анализа были выделены внешность (прическа, одежда, лишний вес); потребности в продуктах, предметах гигиены; семейные отношения; хозяин и его домашний питомец; виды деятельности на изоляции; дистанционная работа из дома.

Популярный в течение последних лет мем «Битва при Алди» в пандемию переосмысливается и перерождается

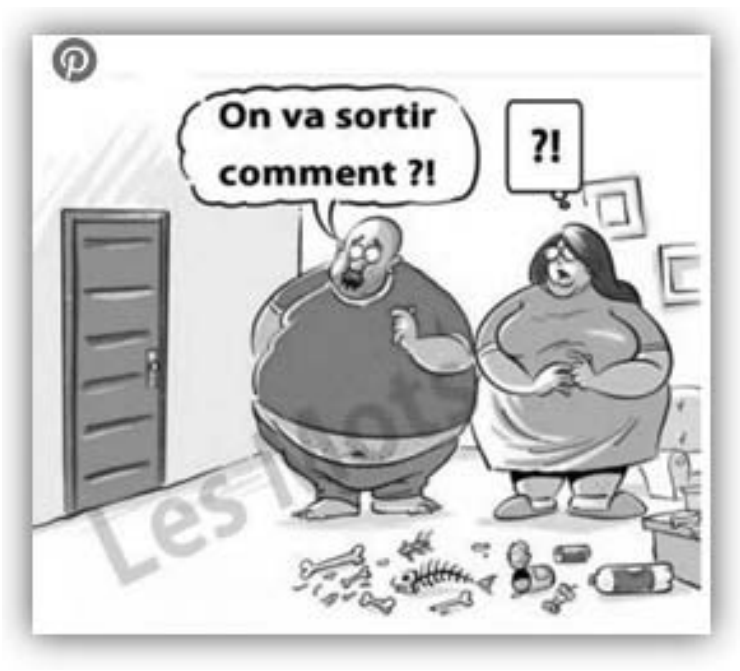

Рис. 2. «Как же мы отсюда выйдем?» 
в мем «Битва в Ашане» (см. Рис. 1). Прецедентная ситуация (ALDI - немецкая продуктовая сеть супермаркетов с самыми низкими ценами, которая недавно пришла на американский рынок) помогает понять, что исходный мем эксплицирует ироничное отношение французов к чрезмерной экономности немцев и американцев. Неоклассический барельеф и существительное bataille c предлогом de - аллюзия на наполеоновские войны и череду франко-прусских войн - эксплицируют второй прецедентный контекст, отсылающий к истории отношений Франции и Германии, которая изобилует жестокими сражениями. Мем «Сражение при Ашане», по нашему мнению, оказывает больший экспрессивный эффект за счет взаимодействия вербальной и визуальной части, ведь «историческое» жесткое сражение идет уже на территории Франции (Ашан - крупнейшая сеть супермаркетов во Франции). Этот пример выражает отношение людей, названных исследователями «ковид-паникерами», которые испытывают панику и воспринимают ситуацию как борьбу за выживание.

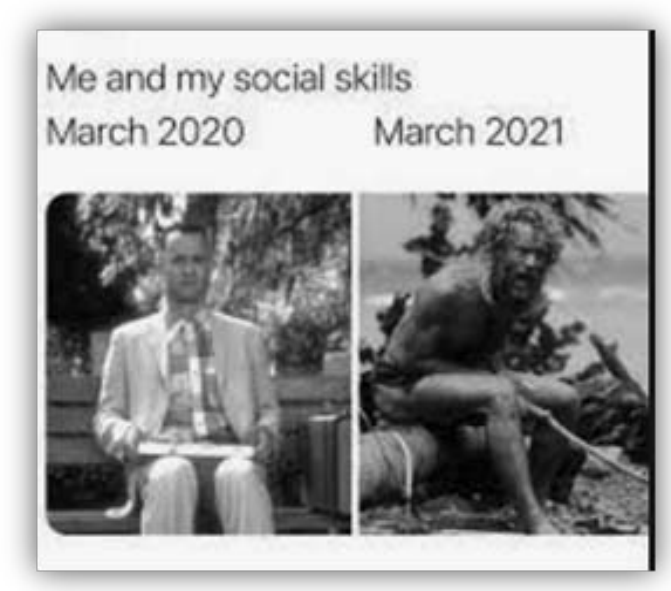

Рис.3. «Я и мои социальные навыки: март 2020 vs март 2021»

Неизбежные проблемы, возникающие у среднестатистического человека во время вынужденного пребывания дома - набор лишнего веса из-за недостатка движения (см. Рис. 2) и исчезновение социальных навыков из-за недостатка общения (см. Рис. 3). Данные мемы выражают настроения другой группы людей, которую мы по эвристическому признаку относим к ковид-лоялистам. Они приняли необходимость соблюдения ограничительных мер и максимально отгородились от пандемии, но не приняли экзистенциальный вызов и утратили свои физические и социальные навыки, в противоположность стойким ковид-скептикам, которые проживают новый экзистенциальный опыт с оптимизмом и спокойствием, думая о красоте и комфорте своего дома и семьи (см. Рис. 4 - запущенный английский сад превращается всего за 2 недели в превосходный французский парк, и все это - благодаря изоляции! и Рис. 5 - Новый год надо встречать с супругом в уютных и красивых халатах).

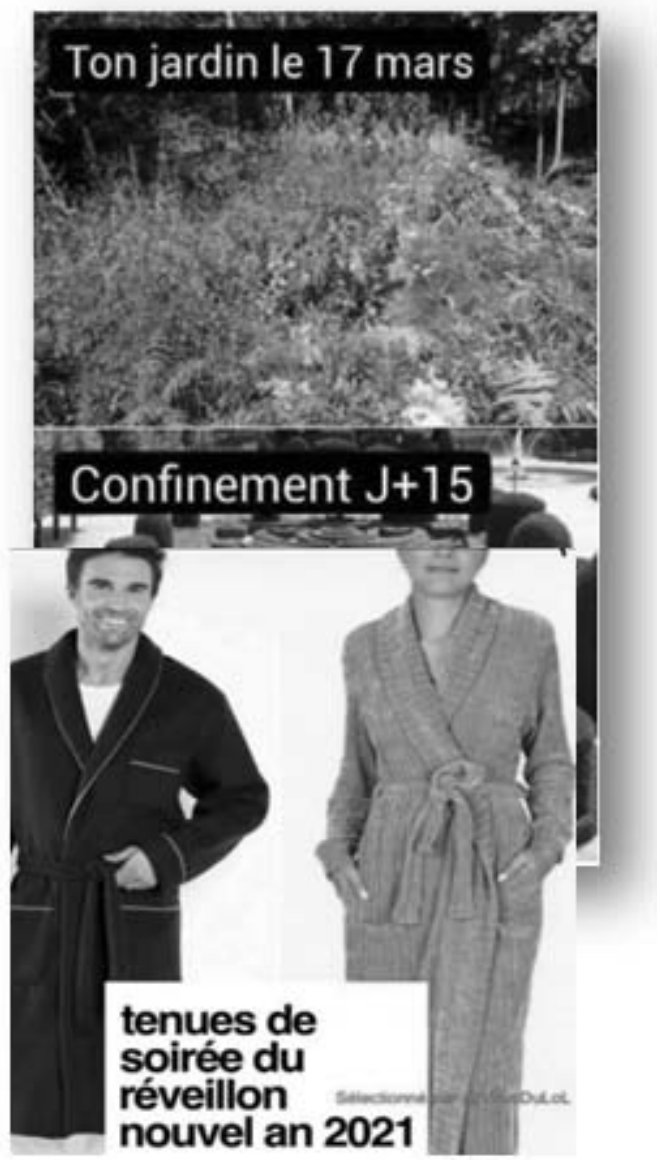

Рис. 4. Английский сад

Рис. 5. Новый год в новых халатах

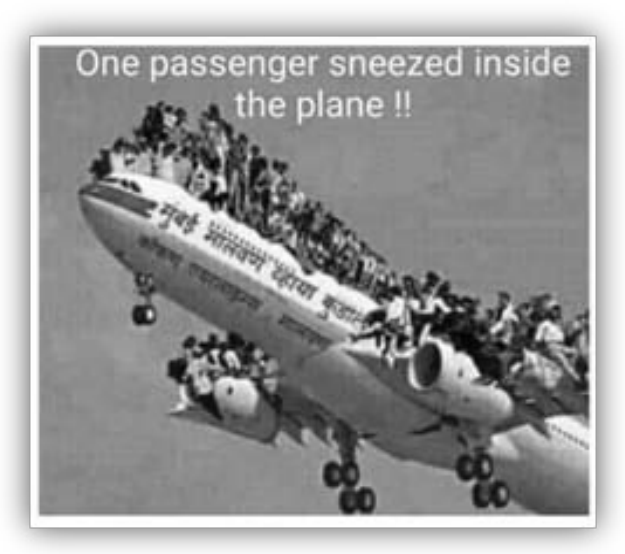

Рис. 6. Один пассажир чихнул в самолете!!

Во всех интернет-мемах для кодирования информации используется когнитивный механизм компрессии информации, изначально базирующийся на международном фоновом знании о специфике и сложностях жизни в период пандемии, а также на культурных реа- 
лиях, характерных для представителей определенных национальностей, также необходимых для корректного инферирования значения подобного элемента виртуального дискурса. Кроме того, для успешного (де)кодирования информации, заложенной в интернет-мемах, может быть использована теория концептуальной интеграции [Fauconnier 1985], согласно которой в результате протекания определенного когнитивного процесса конечное значение сложносоставного элемента дискурса (в нашем случае мультимодальных мемов) образовывается на основании модели четырех пространств, содержащей два исходных ментальных пространства, общее пространство и интегрированное пространство. Измененный смысл полимодального элемента дискурса образовывается в результате проекции значения элемента первого исходного ментального пространства на значение элемента второго, или в результате слияния их значений.

Напр., на рис. 6 невербальный компонент представляет собой изображение летящего самолета, облепленного людьми; вербальный элемент - это фраза «Один пассажир чихнул в самолете!!». Общее пространство: «опасность»; исходное пространство 1: полет вне салона самолета опасен, но при определенных условиях люди готовы на это пойти; исходное пространство 2: в период пандемии чихнувший пассажир крайне опасен; интегрированное пространство: ковид-паникеры настолько боятся заражения COVID-19, что при малейших признаках наличия инфекции способны необдуманно совершать гораздо более опасные поступки.

Таким образом, когнитивной основой мемов периода пандемии является концепт «человек», заключающий в себе аспекты денотации, которые актуализируют в мемах элементы картины коллективного сознания различных социальных групп. Интернет-мемы периода пандемии 2020-2021 могут рассматриваться как анонимный способ массовой коммуникации с особенными прагматико-когнитивными характеристиками. Для более объемного исследования феномена интернет-мемов, связанных с пандемией COVID-19, необходимы междисциплинарные исследования и более обширная выборка мемов на других языках.

\section{ЛИТЕРАТУРА}

1. Воронов В.М. Пандемия covid-19 как экзистенциальное и культурное событие: группы, культурные границы и феномен настроения (на примере российского общества) // Журнал Фронтирных Исследований. 2021. № 1. С. 41-68.

2. Канашина С.В. Интернет-мем как новый вид полимодального дискурса в интернет-коммуникации (на материале английского языка): дис. ...канд. филол. наук. М.: МГЛУ, 2016. 265 с.

3. Марченко Н.Г. Интернет-мем как хранилище культурных кодов сетевого сообщества // Казанская наука. 2013. № 1. С. 113-115.

4. Рябых Е.Б. К вопросу о мультимодальной метафоре (на примере социальной рекламы) // Когнитивные исследования языка. 2019. № 38. С. 162-169.

5. Таймур М.П. Смешанная метафора и малафора в когнитивной анти-меметике на материале английского языка // Филологические науки. Вопросы теории и практики. 2020. Том 13. № 5. С. 236-240.

6. Fauconnier G. Mental Spaces Text. UK: Cambridge, Mass.: MIT Press, 1985. 258 p. 